\title{
Evaluation of karstic aquifers contribution to streams by the statistical analysis of recession curves
}

\author{
A Cem KoC \\ Pamukkale University, Civil Engineering Department, Kinikli Kampusu, 20017 Denizli, Turkey.
}

\begin{abstract}
Karstic aquifers significantly contribute to streams in most of Turkey's river basins, so studies on karst water resources have great importance for Turkey. Karstic aquifer contributions are generally emerging at several locations near the river bed and are not readily measured by direct hydrometric methods. In this study, the extent of karstic aquifer contributions to a stream will be investigated by the statistical analysis of recession coefficients of recession curves. Six stream gauging stations on different streams in the western Mediterranean region of Turkey are selected. Recession periods of the streams are simulated by exponential and quadratic recession curve models. Recession coefficient series of the stream gauging stations are statistically investigated. The comparison of various statistical parameters shows that the recession coefficient series are fairly related to the karstic aquifer contributions. Especially, the measure of spread parameters, standard deviation and interquartile range of recession coefficient series are related to the extent of the karstic aquifer contributions to streams.
\end{abstract}

\section{Introduction}

Surface and subsurface karst terrains, which cover about one-third of Turkey, belong to the Mediterranean hole of the Alpine orogenic belt. Most of the carbonate rocks of the southern part of Turkey are highly karstified (Elhatip 1997). Karstic aquifers significantly contribute to streams in some of Turkey's river basins. Ten out of 26 Turkish surface hydrological basins contain karstic aquifers. Approximately $1 / 3$ of the gross potential of these basins is raised from karstic aquifers with a contribution ratio from $6 \%$ to $60 \%$ of the total water potential of the basins (Baran et al 1995).

Most of the karstic aquifer contributions are emerging at several locations near the river bed and are not readily measured by direct hydrometric methods. Various indirect evaluations such as comparison of specific discharges of basins to those of upstream or neighbouring basins, description of karst spring flow through parameters of single or reversible linear bivariate regression between observed data of two stream gauging stations and water budget balance, have been applied to assess the karstic aquifer contributions to a stream.

The separation of components of a stream discharge gathering from various storages is extremely complex (Griffiths and Clausen 1997). Complexity of the karstification phenomena in the underlying carbonates in most karst regions makes it very difficult to determine the boundaries of underground catchment areas of large karst springs, aquifers and rivers (Elhatip 1997).

Natural climatic variations, anthropogenic influences and land use changes affect the recession coefficient of a recession curve from one year to another. Karstic aquifers are consisting highly permeable fractures, faults and karst channels in carbonate rocks (Kiraly 2003). This formation allows the storage of plenty of water in the karstic voids or transportation of water between the neighbouring basins. So the fluctuation effect of the surface events on the recession coefficient is reduced by karstic aquifer contributions. The variability of recession coefficients of a stream in a karstic area

Keywords. Recession curve; karstic aquifer; western Mediterranean Basin-Turkey; data analysis; hydrology; modelling. 

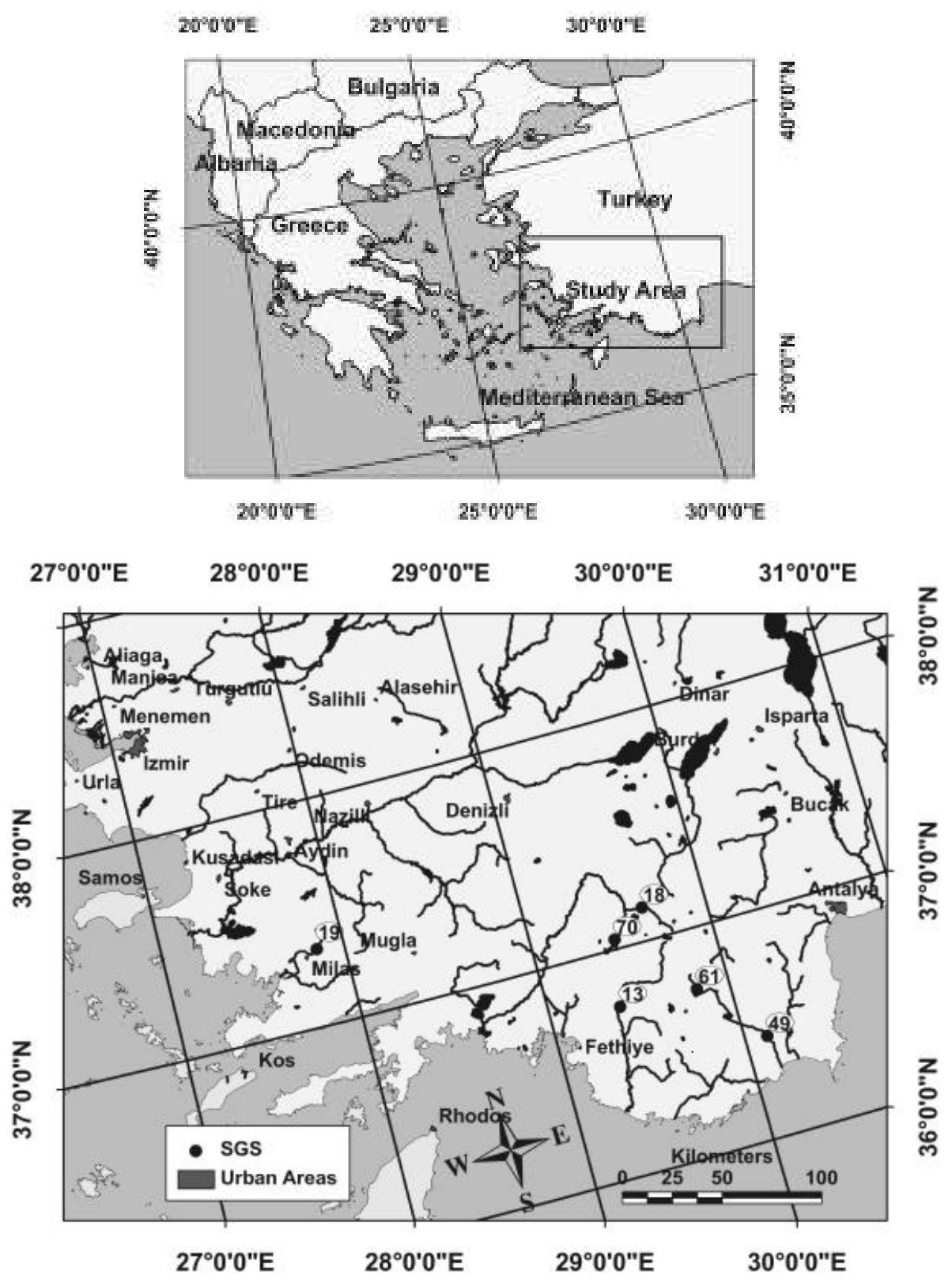

Figure 1. Locations of SGSs.

can give an idea about the volume of a karstic aquifer.

In the present study, the recession coefficients of recession curve series are analyzed statistically and the extent of karstic aquifer contributions are determined. The hypothesis of the more karstic aquifer contribution to a stream, the more regular or alike recession curve parameters one year to another, is investigated.

To show the validity of the hypothesis, recession hydrographs of six stream gauging stations in the western Mediterranean region of Turkey are investigated statistically. Recession hydrographs are modelled with two simple recession curve models and recession coefficients are obtained.
Descriptive statistical parameters of the recession coefficients such as mean, standard deviation, coefficient of skewness are calculated and box plots of the recession coefficients are drawn and the probability plot correlation coefficients of recession coefficients are also calculated. The relationship between the statistical parameters and karstic aquifer contributions are discussed.

\section{Description of the study area and data}

This study was carried out in the western Mediterranean region in southwest Turkey (figure 1). 
Table 1. SGSs used in the study.

\begin{tabular}{|c|c|c|c|c|c|c|}
\hline SGS number & 13 & 18 & 19 & 49 & 61 & 70 \\
\hline $\begin{array}{l}\text { SGS name } \\
\text { (Stream) }\end{array}$ & $\begin{array}{l}\text { Orenkoy } \\
\text { (Esen) }\end{array}$ & $\begin{array}{l}\text { Ballik Pass } \\
\text { (Ballik) }\end{array}$ & $\begin{array}{l}\text { Kocakavak } \\
\text { (Saricay) }\end{array}$ & $\begin{array}{l}\text { Gokbuk } \\
\text { (Basgoz) }\end{array}$ & $\begin{array}{l}\text { Mumur } \\
\text { (Mumur) }\end{array}$ & $\begin{array}{l}\text { Yaprakli } \\
\text { (Horzum) }\end{array}$ \\
\hline Latitude (N) & $36^{\circ} 45^{\prime} 00^{\prime \prime}$ & $37^{\circ} 13^{\prime} 04^{\prime \prime}$ & $37^{\circ} 20^{\prime} 00^{\prime \prime}$ & $36^{\circ} 27^{\prime} 00^{\prime \prime}$ & $36^{\circ} 44^{\prime} 00^{\prime \prime}$ & $37^{\circ} 02^{\prime} 23^{\prime \prime}$ \\
\hline Longitude (E) & $29^{\circ} 23^{\prime} 00^{\prime \prime}$ & $29^{\circ} 40^{\prime} 01^{\prime \prime}$ & $27^{\circ} 50^{\prime} 00^{\prime \prime}$ & $30^{\circ} 07^{\prime} 00^{\prime \prime}$ & $29^{\circ} 48^{\prime} 00^{\prime \prime}$ & $29^{\circ} 27^{\prime} 30^{\prime \prime}$ \\
\hline Drainage area $\left(\mathrm{km}^{2}\right)$ & 807.0 & 126.2 & 145.0 & 222.2 & 260.2 & 372.8 \\
\hline Altitude $(\mathrm{m})$ & 190 & 1091 & 66 & 208 & 1030 & 1018 \\
\hline Precipitation (mm/year) & 615 & 475 & 775 & 554 & 522 & 577 \\
\hline Baseflow (mm/year) & 492 & 175 & 74 & 142 & 0 & 347 \\
\hline $\begin{array}{l}\text { Observation period } \\
\text { (No. of considered years) }\end{array}$ & $\begin{array}{l}1961-1984 \\
(23)\end{array}$ & $\begin{array}{l}1967-2001 \\
(33)\end{array}$ & $\begin{array}{l}1968-1986 \\
(18)\end{array}$ & $\begin{array}{l}1965-1999 \\
(31)\end{array}$ & $\begin{array}{l}1970-2000 \\
(27)\end{array}$ & $\begin{array}{l}1973-1990 \\
(17)\end{array}$ \\
\hline
\end{tabular}

This basin is called as the Independent Western Mediterranean Waters. Karstic aquifer contributions are considerable; $33 \%$ of the total water potential comes from karstic aquifers in the basin (Baran et al 1995). The southern cost fringes enjoy the Mediterranean climate featuring hot, dry summers and mild, rainy winters. The study area gets less than one day snow in a year and the snow cover stays less than one day so the effect of the snow melt will be neglected in this study.

Six stream gauging stations (SGSs) of the Turkish State Hydraulic Works (DSI) are selected for the study. The locations of the SGSs are shown in figure 1. Names of the SGSs and the streams, coordinates, drainage areas, altitudes of the SGSs, mean annual total precipitations at the SGSs' locations and baseflows of the basins obtained from the previous studies are given in table 1 .

Measurement period of each SGS and record lengths are also given in table 1, measurements of some years are not taken into consideration because of the improper data such as dam influence, insufficient recession curve, etc. Any year mentioned herein imply the hydrologic year which starts on 1 October of the previous calendar year and ends on 30 September. Daily mean discharge measurements are used in the study (DSI 1961 to 2001).

According to the daily stream measurements upstream of the SGSs 13, 18, 49 and 70 are of perennial character and upstream of the SGSs 19 and 61 are of intermittent character. Although the Horzum Creek (SGS 70) dried out for five days in September 1977, it is not an intermittent stream.

Previous studies showed that upstream of SGSs 13, 18, 19, 49 and 70 are contributed by karstic aquifers. A previous study (Baran et al 1995) exposed that mean karstic spring contributions are $12.6 \mathrm{~m}^{3} / \mathrm{s}, 0.7 \mathrm{~m}^{3} / \mathrm{s}, 1.0 \mathrm{~m}^{3} / \mathrm{s}$ and $4.1 \mathrm{~m}^{3} / \mathrm{s}$ for SGSs 13, 18, 49 and 70 respectively. That study was based on the comparison of specific discharges of basins with those upstream or neighbouring basins.
Another previous study (Barut and Gürpınar 2005) based on water budget which was performed in Saricay Basin (SGS 19) showed that mean baseflow is $0.34 \mathrm{~m}^{3} / \mathrm{s}$. This stream is contributed by small volume karstic aquifers and baseflow becomes zero in some dry years. There is no karstic spring contribution reported by the previous studies conducted for the upstream of the SGS 61.

\section{Recession curves}

The recession studied here is not only baseflow recession, but the recession of total flow, so the 'recession curve' will denote the complete decreasing part of the hydrograph. Recession segments are selected from the daily mean discharge hydrographs as shown in figure 2. Figure 2 shows the hydrographs and the recession segments of the SGSs for the years 1979-1984. Recession period of the studied streams usually starts after the winter rains (end of March) and goes on until the start of the summer (end of May). In this study, a recession period started at a peak discharge value and lasted until stream flow began to increase or recession curve flattened. Start and finish days of recession periods of all SGSs are given in table 2 .

\subsection{Modelling the recession period}

Stream recession flow of a single linear reservoir is commonly characterized by the exponential equation or in the alternative power form equation. However, in reality the groundwater dynamics of even the simplest aquifers may behave in a nonlinear fashion (Mishra et al 2004). Among the plenty of very successful linear, nonlinear and multi-linear storage-discharge relationship models (Chapman 1999, 2003; Wittenberg 1999, 2003), or probabilistic approach to modelling of recession curves (Aksoy et al 2001), two simple models are selected to represent the recession curves in this study. 

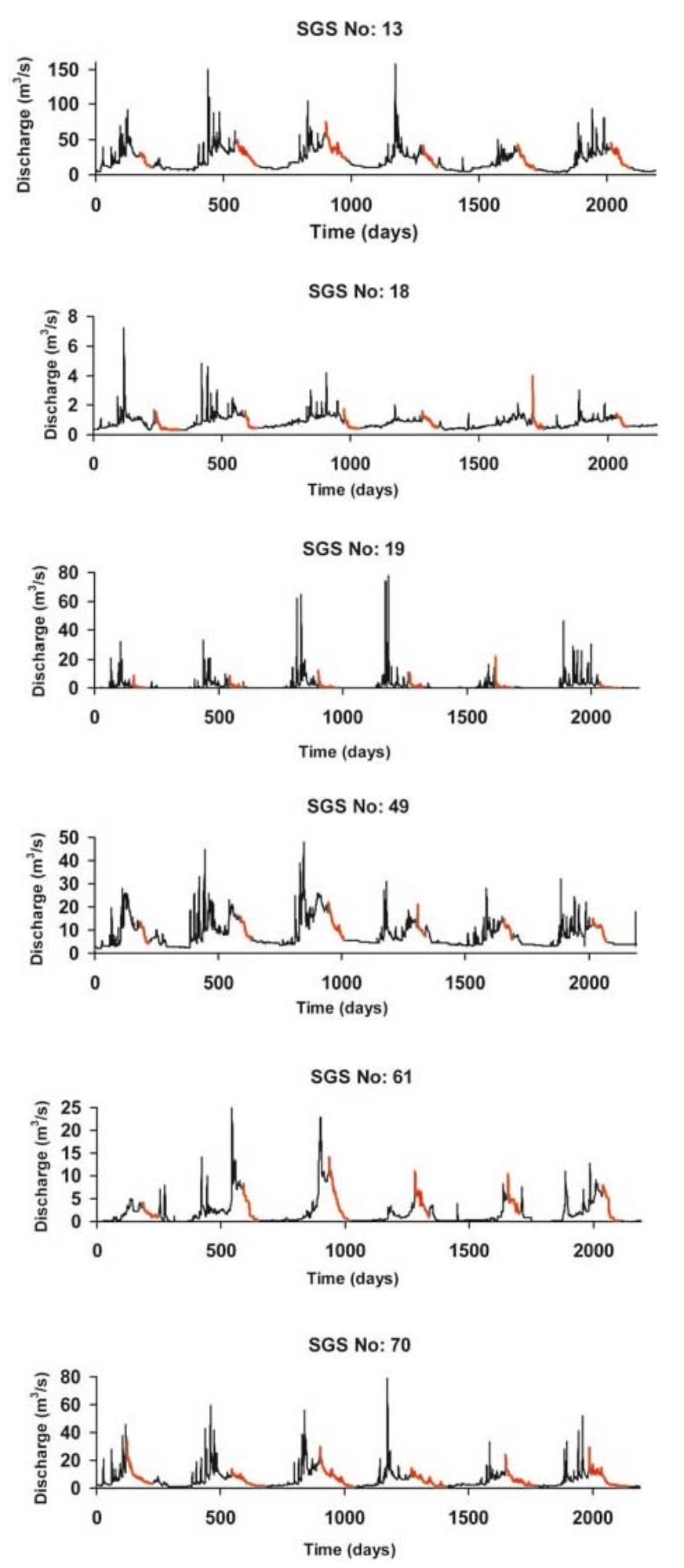

Figure 2. Daily mean discharges and selected recession periods (red lines) from 1979 to 1984.

The first model is the well-known Maillet formula given in

$$
Q_{t}=Q_{0} \exp \left(-\alpha_{e} t\right)
$$

where $Q_{t}$ is the discharge $t$ days after the recession period started, $Q_{0}$ is the initial discharge, $\alpha_{e}$ is the recession coefficient of the exponential model and $t$ is time. This approximate analytical solution is proposed by Boussinesq. Maillet approximated the aquifer recession curve using an analogue model of a water-filled single reservoir emptying through a porous plug (Dewandel et al 2003). This model will be called as the exponential model from now on.

The second model, a quadratic equation, based on the solution of the general differential equation of the non-artesian flow in one dimensional homogenous aquifer with horizontal bottom is given by

$$
Q_{t}=\frac{Q_{0}}{\left(1+\alpha_{q} t\right)^{2}}
$$

where $Q_{t}$ is the discharge $t$ days after the recession period started, $Q_{0}$ is the initial discharge, $\alpha_{q}$ is the recession coefficient of the quadratic model and $t$ is the time. This will be called as the quadratic model from now on (Werner and Sundquist 1951).

\subsection{Calibration of nonlinear recession curve models}

Nonlinear optimization is to minimize a function. Numerical methods for nonlinear optimization problems are iterative. Consider a system of nonlinear equations as shown in

$$
\min _{x \in \Re^{n}} f_{i}(x),
$$

where $f_{i}(x)=0 \quad(i=1, \ldots, m)$ are continuous differentiable functions in $\Re^{n}$. We try to compute a least square solution, which means we need to solve the nonlinear least squares problem of

$$
\min _{x \in \Re^{n}}\|F(x)\|_{2}^{2},
$$

where $F(x)=\left(f_{1}(x), \ldots, f_{m}(x)\right)^{T}$ and $\|\cdot\|_{2}$ is the Euclidian norm. The Gauss-Newton (GN) method for the problem which is shown in equation (4) is iterative and at the current iterate $x_{k}$, the GN step is given as

$$
d_{k}=-\left(A\left(x_{k}\right)^{T}\right)^{-1} F\left(x_{k}\right),
$$

where $A(x)=\nabla F(x)^{T}$ is the Jacobi matrix. It is easy to see that the GN step is the minimum norm solution of the subproblem as given in

$$
\min _{d \in \Re^{n}}\left\|F\left(x_{k}\right)+A\left(x_{k}\right)^{T} d\right\|_{2}^{2},
$$

which is an approximation to the original problem given in equation (4) near the current iterate 
Table 2. Start and finish days of recession segments.

\begin{tabular}{|c|c|c|c|c|c|c|c|c|c|c|c|c|}
\hline \multirow[b]{3}{*}{ Year } & \multicolumn{12}{|c|}{ Stream gauging station no. } \\
\hline & \multicolumn{2}{|c|}{13} & \multicolumn{2}{|c|}{18} & \multicolumn{2}{|c|}{19} & \multicolumn{2}{|c|}{49} & \multicolumn{2}{|c|}{61} & \multicolumn{2}{|c|}{70} \\
\hline & Start & Finish & Start & Finish & Start & Finish & Start & Finish & Start & Finish & Start & Finish \\
\hline 1961 & 195 & 253 & & & & & & & & & & \\
\hline 1962 & 170 & 254 & & & & & & & & & & \\
\hline 1963 & 182 & 267 & & & & & & & & & & \\
\hline 1964 & 154 & 214 & & & & & & & & & & \\
\hline 1965 & 199 & 253 & & & & & 181 & 212 & & & & \\
\hline 1966 & 188 & 254 & & & & & & & & & & \\
\hline 1967 & 234 & 292 & 233 & 304 & & & & & & & & \\
\hline 1968 & 203 & 274 & 203 & 253 & 165 & 230 & & & & & & \\
\hline 1969 & 202 & 254 & 225 & 305 & 201 & 257 & 168 & 213 & & & & \\
\hline 1970 & 196 & 254 & 201 & 287 & 172 & 260 & 172 & 212 & 195 & 261 & & \\
\hline 1971 & 191 & 265 & 228 & 271 & 182 & 271 & 144 & 166 & 211 & 298 & & \\
\hline 1972 & 160 & 240 & 194 & 273 & 159 & 236 & 159 & 188 & 254 & 277 & & \\
\hline 1973 & 167 & 235 & 208 & 283 & 150 & 226 & 149 & 174 & 201 & 253 & 151 & 243 \\
\hline 1974 & 190 & 263 & 195 & 287 & 167 & 246 & 165 & 188 & 189 & 241 & 190 & 305 \\
\hline 1975 & 187 & 249 & 232 & 293 & 162 & 195 & 144 & 189 & 186 & 265 & 144 & 300 \\
\hline 1976 & 198 & 231 & 198 & 259 & 121 & 181 & 206 & 254 & 198 & 262 & 197 & 328 \\
\hline 1977 & 205 & 261 & 205 & 255 & 153 & 258 & 205 & 248 & 204 & 238 & 204 & 312 \\
\hline 1978 & & & & & & & & & & & & \\
\hline 1979 & 177 & 219 & 244 & 332 & 158 & 216 & 186 & 216 & 185 & 246 & 124 & 223 \\
\hline 1980 & 190 & 265 & 225 & 271 & 179 & 234 & 225 & 268 & 225 & 282 & 180 & 314 \\
\hline 1981 & 171 & 253 & 244 & 303 & 171 & 253 & 216 & 277 & 204 & 287 & 171 & 305 \\
\hline 1982 & 185 & 241 & 184 & 244 & 174 & 227 & 211 & 243 & 185 & 243 & 175 & 314 \\
\hline 1983 & 191 & 263 & 248 & 291 & 154 & 229 & 196 & 230 & 195 & 242 & 189 & 310 \\
\hline 1984 & 191 & 264 & 210 & 251 & 210 & 281 & 191 & 245 & 214 & 281 & 162 & 316 \\
\hline 1985 & & & 195 & 273 & 137 & 222 & 195 & 237 & 193 & 247 & 171 & 307 \\
\hline 1986 & & & 189 & 275 & 146 & 230 & 147 & 190 & 185 & 248 & 147 & 306 \\
\hline 1987 & & & 215 & 267 & & & 213 & 261 & 220 & 263 & 185 & 297 \\
\hline 1988 & & & 215 & 246 & & & 199 & 235 & 213 & 261 & 198 & 304 \\
\hline 1989 & & & 186 & 262 & & & 177 & 204 & 177 & 211 & 177 & 309 \\
\hline 1990 & & & 189 & 256 & & & 151 & 177 & 166 & 186 & 152 & 270 \\
\hline 1991 & & & 200 & 288 & & & 190 & 220 & & & & \\
\hline 1992 & & & 203 & 268 & & & 203 & 240 & 195 & 249 & & \\
\hline 1993 & & & & & & & 222 & 258 & 225 & 257 & & \\
\hline 1994 & & & 223 & 317 & & & 181 & 213 & 205 & 238 & & \\
\hline 1995 & & & 219 & 276 & & & 183 & 214 & & & & \\
\hline 1996 & & & 200 & 277 & & & 131 & 156 & 199 & 238 & & \\
\hline 1997 & & & 201 & 252 & & & 182 & 200 & & & & \\
\hline 1998 & & & 207 & 265 & & & 225 & 264 & 209 & 263 & & \\
\hline 1999 & & & 208 & 254 & & & 147 & 178 & 201 & 286 & & \\
\hline 2000 & & & 218 & 301 & & & & & 196 & 245 & & \\
\hline 2001 & & & 196 & 264 & & & & & & & & \\
\hline Mean & 188 & 253 & 210 & 276 & 165 & 236 & 183 & 218 & 201 & 254 & 172 & 298 \\
\hline
\end{tabular}

$x_{k}$. One difficulty of using the GN step is that the Jacobi matrix $A\left(x_{k}\right)$ may be ill-conditioned, which normally leads to a very big step $d_{k}$ causing the algorithm to break or fail in line searches. The Levenberg-Marquardt (LM) method chooses the step as shown in

$$
d_{k}=-\left(A\left(x_{k}\right) A\left(x_{k}\right)^{T}+\lambda_{k} I\right)^{-1} A\left(x_{k}\right) F\left(x_{k}\right),
$$

where $\lambda_{k} \geq 0$ is a parameter which is updated from iteration to iteration. The original idea at LM method is to introduce the parameter $\lambda_{k}$ to overcome the ill-condition of $A\left(x_{k}\right)$ or to prevent $\left\|d_{k}\right\|_{2}$ being too large. Equation (7) is a solution of the subproblem given in

$$
\min _{d \in \Re^{n}}\left\|F\left(x_{k}\right)+A\left(x_{k}\right)^{T} d\right\|_{2}^{2}+\lambda_{k}\|d\|_{2}^{2},
$$

which is a modification of equation (6). The additional term $\lambda_{k}\|d\|_{2}^{2}$ can be viewed as a penalty term which prevents $\left\|d_{k}\right\|$ from being too large. Define 
a positive scalar $\Delta_{k}$ as given in

$$
\Delta_{k}=\left\|\left(A\left(x_{k}\right) A\left(x_{k}\right)^{T}+\lambda_{k} I\right)^{-1} A\left(x_{k}\right) F\left(x_{k}\right)\right\|_{2} .
$$

Then for any $\|d\|_{2} \leq \Delta_{k}, d_{k}$ is a solution of equation (8) and also a solution of the problem given in

$$
\min _{d \in \Re^{n}}\left\|F\left(x_{k}\right)+A\left(x_{k}\right)^{T} d\right\|_{2}^{2},
$$

which is a trust region (TR) subproblem. A TR algorithm for nonlinear least squares is similar to the LM method, except that the bound $\Delta_{k}$ is updated from iteration to iteration instead of the parameter $\lambda_{k}$ (Yuan 1994).

In the present study, the parameters of both models are calibrated by the TR method by means of the Curve Fitting Toolbox (CFT) of MATLAB ${ }^{\circledR}$. In the CFT, TR, LM and GN algorithms are available for nonlinear least squares curve fitting calculations.

While all three algorithms are based on Newton's method, the TR method has some advantages on the others (the MathWorks 2005). The GN method is not always reliable particularly in the presence of insufficient data, topological or parameter errors. The TR formulation is more robust than the GN method (Pajic and Clements 2005).

Adjusted determination coefficient $\left(A R^{2}\right)$ is used as a goodness of fit measure. $A R^{2}$ is the proportion of variance of the dependent variable that is explained by the independent variables as given in

$$
\begin{aligned}
& A R^{2}=1-\frac{S S E(n-1)}{S S y(n-p)}, \\
& S S E=\sum_{i=1}^{n}\left(y_{i}-\hat{y}_{i}\right)^{2}, \\
& S S y=\sum_{i=1}^{n}\left(y_{i}-\bar{y}\right)^{2},
\end{aligned}
$$

where $S S E$ is the sum of squares due to error, $S S y$ is the sum of squares about the mean, $n$ is the number of data points, $p$ is the number of model parameters, $y_{i}$ and $\hat{y}_{i}$ are the observed and fitted data values, respectively and $\bar{y}$ is the mean of the observed data values.

According to the aforesaid explanations the model coefficients $\left(Q_{0}\right.$ and $\alpha_{e}$ or $\left.\alpha_{q}\right)$ of both models are computed for each SGS. As an example, 1981 year measurements of the SGS 61 will be examined in detail. The 1981 water year is from day 732 to 1096 (figure 2). The recession period is also shown in figure 2. Discharges were divided by the peak

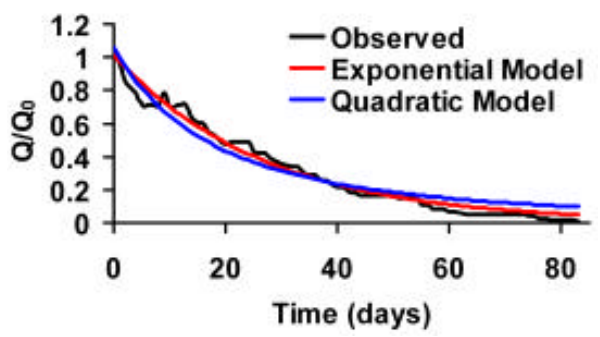

Figure 3. Observed and model recession hydrographs of SGS 61 for the year of 1981.

discharge value to present the recession hydrograph values as the ratio of the starting value as shown in figure 3 .

Model parameters are calculated by using the TR algorithm. The parameters of exponential and quadratic models are found as

$$
\begin{aligned}
Q_{t} & =1.013 \exp (-0.037 t), \\
Q_{t} & =\frac{1.057}{(1+0.028 t)^{2}} .
\end{aligned}
$$

$A R^{2}$ values for the exponential and quadratic models are 0.98 and 0.92 respectively. Recession hydrographs of the models are shown in figure 3 from which it is seen that both models adequately fit.

Model parameters are calculated in the same way for other SGSs and given in table 3. Then the recession coefficients $\left(\alpha_{e}\right.$ and $\left.\alpha_{q}\right)$ of both models are obtained. Initial discharges $\left(Q_{0}\right)$ are obtained from models but not used in this study. Mean $Q_{0}$ values are given in table 3 .

\section{Statistical analysis of recession coefficients}

Recession coefficients of the SGSs are arranged as series and analyzed statistically. Simple summarization methods are applied to $\alpha_{e}$ and $\alpha_{q}$ series. Mean $(\bar{\alpha})$ is used as the measure of location, standard deviation $\left(\sigma_{\alpha}\right)$ is used as the measure of spread and the coefficient of skewness $C_{s, \alpha}$ is used as the measure of skewness. Calculated values of the mean, standard deviation and skewness of $\alpha_{e}$ and $\alpha_{q}$ series are given in table 3 .

In addition determining the normality of $\alpha_{e}$ and $\alpha_{q}$ series, probability plot correlation coefficient (PPCC) values $(r)$ are calculated using

$$
r=\frac{\sum_{i=1}^{n}\left(\alpha_{i}-\bar{\alpha}\right)\left(w_{i}-\bar{w}\right)}{\left[\sum_{i=1}^{n}\left(\alpha_{i}-\bar{\alpha}\right)^{2} \sum_{i=1}^{n}\left(w_{i}-\bar{w}\right)^{2}\right]^{1 / 2}},
$$


Table 3. Recession coefficients, descriptive statistics, PPCC (r) and mean $Q_{0}$ values.

\begin{tabular}{|c|c|c|c|c|c|c|c|c|c|c|c|c|}
\hline \multirow[b]{3}{*}{ Year } & \multicolumn{12}{|c|}{ Stream gauging station no. } \\
\hline & \multicolumn{2}{|c|}{13} & \multicolumn{2}{|c|}{18} & \multicolumn{2}{|c|}{19} & \multicolumn{2}{|c|}{49} & \multicolumn{2}{|c|}{61} & \multicolumn{2}{|c|}{70} \\
\hline & $\alpha_{e}$ & $\alpha_{q}$ & $\alpha_{e}$ & $\alpha_{q}$ & $\alpha_{e}$ & $\alpha_{q}$ & $\alpha_{e}$ & $\alpha_{q}$ & $\alpha_{e}$ & $\alpha_{q}$ & $\alpha_{e}$ & $\alpha_{q}$ \\
\hline 1961 & 0.016 & 0.010 & & & & & & & & & & \\
\hline 1962 & 0.008 & 0.005 & & & & & & & & & & \\
\hline 1963 & 0.007 & 0.004 & & & & & & & & & & \\
\hline 1964 & 0.006 & 0.003 & & & & & & & & & & \\
\hline 1965 & 0.015 & 0.009 & & & & & 0.005 & 0.003 & & & & \\
\hline 1966 & 0.014 & 0.010 & & & & & & & & & & \\
\hline 1967 & 0.012 & 0.008 & 0.016 & 0.011 & & & & & & & & \\
\hline 1968 & 0.013 & 0.008 & 0.027 & 0.019 & 0.061 & 0.111 & & & & & & \\
\hline 1969 & 0.015 & 0.009 & 0.005 & 0.003 & 0.156 & 0.191 & 0.015 & 0.009 & & & & \\
\hline 1970 & 0.011 & 0.007 & 0.010 & 0.006 & 0.039 & 0.048 & 0.006 & 0.003 & 0.043 & 0.039 & & \\
\hline 1971 & 0.012 & 0.007 & 0.019 & 0.011 & 0.046 & 0.063 & 0.025 & 0.014 & 0.050 & 0.042 & & \\
\hline 1972 & 0.012 & 0.008 & 0.011 & 0.006 & 0.028 & 0.029 & 0.010 & 0.006 & 0.100 & 0.091 & & \\
\hline 1973 & 0.017 & 0.011 & 0.014 & 0.009 & 0.289 & 0.021 & 0.013 & 0.007 & 0.044 & 0.033 & 0.015 & 0.010 \\
\hline 1974 & 0.010 & 0.017 & 0.013 & 0.009 & 0.040 & 0.037 & 0.050 & 0.035 & 0.045 & 0.031 & 0.014 & 0.010 \\
\hline 1975 & 0.014 & 0.009 & 0.018 & 0.012 & 0.139 & 0.139 & 0.011 & 0.006 & 0.034 & 0.027 & 0.010 & 0.006 \\
\hline 1976 & 0.028 & 0.026 & 0.013 & 0.007 & 0.034 & 0.042 & 0.017 & 0.011 & 0.038 & 0.028 & 0.015 & 0.014 \\
\hline 1977 & 0.022 & 0.021 & 0.035 & 0.026 & 0.031 & 0.048 & 0.019 & 0.011 & 0.049 & 0.041 & 0.016 & 0.011 \\
\hline 1978 & & & & & & & & & & & & \\
\hline 1979 & 0.028 & 0.018 & 0.011 & 0.009 & 0.055 & 0.052 & 0.038 & 0.024 & 0.021 & 0.016 & 0.016 & 0.016 \\
\hline 1980 & 0.014 & 0.009 & 0.038 & 0.028 & 0.042 & 0.043 & 0.024 & 0.015 & 0.049 & 0.039 & 0.017 & 0.015 \\
\hline 1981 & 0.011 & 0.007 & 0.023 & 0.017 & 0.042 & 0.085 & 0.019 & 0.013 & 0.037 & 0.028 & 0.017 & 0.014 \\
\hline 1982 & 0.020 & 0.013 & 0.018 & 0.011 & 0.025 & 0.039 & 0.014 & 0.008 & 0.026 & 0.018 & 0.017 & 0.015 \\
\hline 1983 & 0.025 & 0.018 & 0.027 & 0.019 & 0.038 & 0.047 & 0.017 & 0.009 & 0.021 & 0.013 & 0.018 & 0.016 \\
\hline 1984 & 0.020 & 0.014 & 0.026 & 0.016 & 0.033 & 0.032 & 0.011 & 0.006 & 0.078 & 0.087 & 0.019 & 0.022 \\
\hline 1985 & & & 0.014 & 0.010 & 0.019 & 0.015 & 0.032 & 0.022 & 0.049 & 0.047 & 0.020 & 0.021 \\
\hline 1986 & & & 0.007 & 0.004 & 0.039 & 0.041 & 0.020 & 0.012 & 0.043 & 0.034 & 0.014 & 0.012 \\
\hline 1987 & & & 0.033 & 0.022 & & & 0.011 & 0.007 & 0.059 & 0.040 & 0.019 & 0.013 \\
\hline 1988 & & & 0.054 & 0.035 & & & 0.019 & 0.011 & 0.081 & 0.087 & 0.032 & 0.029 \\
\hline 1989 & & & 0.008 & 0.005 & & & 0.037 & 0.024 & 0.085 & 0.063 & 0.009 & 0.006 \\
\hline 1990 & & & 0.010 & 0.006 & & & 0.023 & 0.014 & 0.249 & 0.188 & 0.010 & 0.006 \\
\hline 1991 & & & 0.006 & 0.003 & & & 0.007 & 0.003 & & & & \\
\hline 1992 & & & 0.009 & 0.005 & & & 0.006 & 0.003 & 0.034 & 0.022 & & \\
\hline 1993 & & & & & & & 0.038 & 0.027 & 0.078 & 0.055 & & \\
\hline 1994 & & & 0.008 & 0.005 & & & 0.044 & 0.029 & 0.074 & 0.056 & & \\
\hline 1995 & & & 0.002 & 0.012 & & & 0.005 & 0.003 & & & & \\
\hline 1996 & & & 0.009 & 0.006 & & & 0.042 & 0.031 & 0.061 & 0.046 & & \\
\hline 1997 & & & 0.018 & 0.011 & & & 0.016 & 0.008 & & & & \\
\hline 1998 & & & 0.019 & 0.012 & & & 0.040 & 0.033 & 0.060 & 0.043 & & \\
\hline 1999 & & & 0.022 & 0.015 & & & 0.009 & 0.005 & 0.078 & 0.121 & & \\
\hline 2000 & & & 0.008 & 0.005 & & & & & 0.045 & 0.043 & & \\
\hline 2001 & & & 0.010 & 0.006 & & & & & & & & \\
\hline $\bar{\alpha}$ & 0.015 & 0.011 & 0.017 & 0.012 & 0.064 & 0.060 & 0.021 & 0.013 & 0.060 & 0.051 & 0.016 & 0.014 \\
\hline$\sigma_{\alpha}$ & 0.006 & 0.006 & 0.011 & 0.008 & 0.067 & 0.045 & 0.013 & 0.010 & 0.043 & 0.037 & 0.005 & 0.006 \\
\hline$C_{s, \alpha}$ & 0.810 & 1.106 & 1.421 & 1.365 & 2.674 & 1.907 & 0.753 & 0.955 & 3.450 & 2.276 & 1.391 & 0.960 \\
\hline$r$ & 0.966 & 0.949 & 0.938 & 0.934 & 0.762 & 0.871 & 0.954 & 0.938 & 0.784 & 0.866 & 0.917 & 0.960 \\
\hline$Q_{0}$ & 0.777 & 0.825 & 0.755 & 0.793 & 0.225 & 0.288 & 0.664 & 0.683 & 0.873 & 0.976 & 0.576 & 0.682 \\
\hline
\end{tabular}

where $r$ is the linear correlation coefficient between the ordered observations $\left(\alpha_{i}\right)$ and the corresponding fitted quantiles $\left(w_{i}\right)$ of $\alpha_{e}$ or $\alpha_{q}$ series. Values of $r$ approaching 1.0 suggest that the observations could have been drawn from the fitted distribution. In this study, quantiles are obtained from the cumulative normal distribution function. $\bar{\alpha}$ denotes the average value of the observations and $\bar{w}$ denotes the average value of the fitted quantiles in equation (16).

More robust and resistant to the extreme values, data summarizing techniques may be used besides the classical measures. A very useful and concise graphical display for summarizing the distribution of a data set is the boxplot. Centreline of the box indicates the median which is the measure 

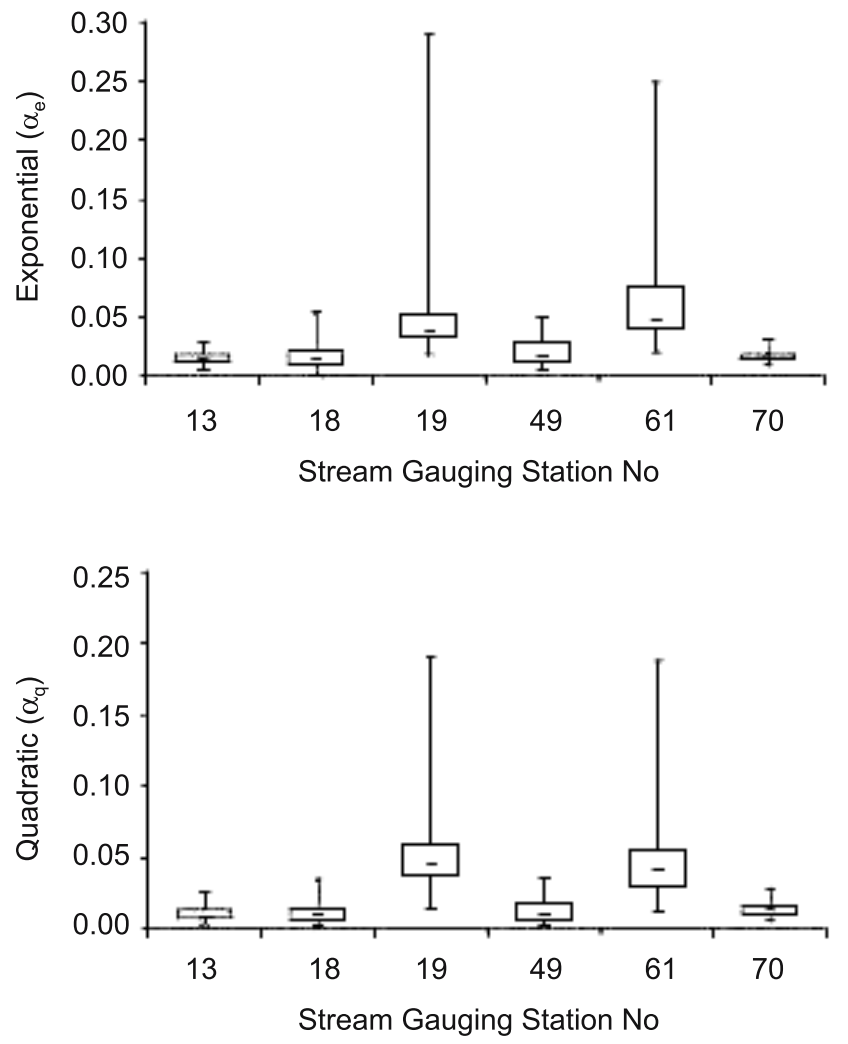

Figure 4. Boxplots of recession coefficients for the exponential and quadratic models.

of location. The box height denotes the interquartile range (IQR) which is the measure of spread. The relative size of box handles shows the quartile skew which is the measure of skewness (Helsel and Hirsch 2002). Boxplots of recession coefficients of $\alpha_{e}$ and $\alpha_{q}$ series are given in figure 4. Simple boxplots are used in this study displaying the minimum, lover quartile, median, upper quartile and the maximum, respectively from bottom to the top of the box.

Boxplots for both models have the same character as shown in figure 4. SGSs can be grouped into three groups for similarities of boxplots. The first group is SGSs 13 and 70, they have small IQR values and the length of box handles are small, the second group is SGSs 18 and 49, their IQR values and the length of box handles are increased. Finally, the third group is SGSs 19 and 61, their IQR values and especially the length of box handles are much more than the others.

\section{Results}

As mentioned previously, karstic aquifers contribute to the upstreams of the SGSs 13, 70, 18, 49, 19 and 61 in the order of decreasing quantity. SGS numbers are listed in descending order due to the karstic aquifer contribution amounts in table 4. Studied streams can be grouped into three classes according to their karstic aquifer contribution amounts as high, medium and low levels; SGSs 13 and 70 can be accepted as high level, SGSs 18 and 49 medium level, SGSs 19 and 61 low level or non-karstic aquifer contributed streams.

The extent of the karstic aquifers contribution to streams will be discussed by comparing various criteria. The first comparison is performed for the measure of location values (mean and median) of $\alpha_{e}$ and $\alpha_{q}$ series. SGS numbers are listed from low to high mean and median values of $\alpha_{e}$ and $\alpha_{q}$ series in table 4 . This arrangement shows that the more karstic aquifer contribution the less $\bar{\alpha}$ or median value of recession coefficients. But recession coefficient of a basin is a characteristic and distinguishing parameter, it depends on various features of basin. Standalone mean or median of the recession coefficients does not seem to be enough to determine the volume of karstic aquifer that contribute to the stream.

The second comparison is performed for the measure of spread values ( $\sigma_{\alpha}$ and IQR) of $\alpha_{e}$ and $\alpha_{q}$ series. SGS numbers are listed from low to high $\sigma_{\alpha}$ and IQR values in table 4 . This arrangement shows that the more karstic aquifer contribution to the streams, the less recession coefficient variation one year to another. Order of IQR values for the quadratic model is exactly the same with the enumeration of karstic aquifer contribution rate values.

The third comparison is performed for the measure of skewness values $\left(C_{s, \alpha}\right)$ of $\alpha_{e}$ and $\alpha_{q}$ series.

Table 4. Listing the SGS numbers due to various parameters (karstic aquifer contribution amount and $r$ are in decreasing order; $\bar{\alpha}$, median, $\sigma_{\alpha}, I Q R$ and $C_{s, \alpha}$ are in increasing order).

\begin{tabular}{|c|c|c|c|c|c|c|c|c|c|c|c|c|}
\hline \multirow{2}{*}{$\begin{array}{c}\text { Karstic aquifer } \\
\text { contribution amount }\end{array}$} & \multicolumn{2}{|c|}{$\bar{\alpha}$} & \multicolumn{2}{|c|}{ Median } & \multicolumn{2}{|c|}{$\sigma_{\alpha}$} & \multicolumn{2}{|c|}{ IQR } & \multicolumn{2}{|c|}{$C_{s, \alpha}$} & \multicolumn{2}{|c|}{$r$} \\
\hline & $\overline{\alpha_{e}}$ & $\alpha_{q}$ & $\alpha_{e}$ & $\alpha_{q}$ & $\overline{\alpha_{e}}$ & $\overline{\alpha_{q}}$ & $\alpha_{e}$ & $\alpha_{q}$ & $\alpha_{e}$ & $\overline{\alpha_{q}}$ & $\alpha_{e}$ & $\alpha_{q}$ \\
\hline 13 & 13 & 13 & 13 & 13 & 70 & 13 & 70 & 13 & 49 & 49 & 13 & 70 \\
\hline 70 & 70 & 18 & 18 & 18 & 13 & 70 & 13 & 70 & 13 & 70 & 49 & 13 \\
\hline 18 & 18 & 49 & 70 & 49 & 18 & 18 & 18 & 18 & 70 & 13 & 18 & 49 \\
\hline 49 & 49 & 70 & 49 & 70 & 49 & 49 & 49 & 49 & 18 & 18 & 70 & 18 \\
\hline 19 & 61 & 61 & 19 & 61 & 61 & 61 & 19 & 19 & 19 & 19 & 61 & 19 \\
\hline 61 & 19 & 19 & 61 & 19 & 19 & 19 & 61 & 61 & 61 & 61 & 19 & 61 \\
\hline
\end{tabular}


SGS numbers are listed in ascending order for $C_{s, \alpha}$ values in table 4 . The SGSs list of $C_{s, \alpha}$ values do not match with the SGSs list of karstic aquifer contribution rate values. Skewness value of the recession coefficients does not seem to be enough to determine the volume of karstic aquifer that contribute to the stream.

The last comparison is performed for the normality $(r)$ values of $\alpha_{e}$ and $\alpha_{q}$ series. SGSs are listed from high to low $r$ values in table 4 . The more karstic aquifer contributed streams the higher $r$ values of $\alpha_{e}$ and $\alpha_{q}$ series, but $r$ values like $C_{s, \alpha}$ values are not successful determining the volume of karstic aquifer that contribute to the stream.

\section{Conclusion}

Whether descriptive statistical parameters of recession coefficients of a stream in the karstic area help to estimate the volume of the aquifer contributing the stream is investigated in this paper. Results of the study show that there is a considerable relationship between some statistical descriptors of the recession coefficients and karstic aquifer volumes. Especially measure of spread statistics seems to be an adequate indicator for the karstic aquifer contributions. Physical explanation of this result can be the regulation effect of water accumulated in the karstic voids or arriving from neighbouring basins via karstic channels. Karstic aquifer contributed streams act as if they were being regulated by a reservoir and less affected by surface effects than other types of aquifer contributed streams. However, this relationship gives a rough estimation about the volume of the aquifer and not a certain value. For a general statement, more similar studies should be performed.

\section{References}

Aksoy H, Bayazıt M and Wittenberg H 2001 Probabilistic approach to modelling of recession curves; Hydrol. Sci. J. $46269-285$.
Baran T, Harmancioglu N and Ozis U 1995 Average base flow rates of karst spring effluents in Turkey; International Symposium and Field Seminar on Karst Waters E Environmental Impacts, September 10-20 Antalya Turkey.

Barut I F and Gürpınar O 2005 An approach to the hydrogeological circulation model of the salty karstic springs in the Milas (Mugla) basin; Univ. Istanbul J. Earth Sci. 1 1-22 (in Turkish).

Chapman T 1999 A comparison of algorithms for stream flow recession and baseflow separation; Hydrol. Process. 13 701-714.

Chapman T G 2003 Modelling stream recession flows; Environ. Modell. Softw. 18 683-692.

Dewandel B, Lachassagne P, Bakalowicz M, Weng $\mathrm{Ph}$ and Al-Malki A 2003 Evaluation of aquifer thickness by analyzing recession hydrographs. Application to the Oman ophiolite hard-rock aquifer; J. Hydrol. 274 248-269.

Elhatip H 1997 The influence of karst features on environmental studies in Turkey; Environ. Geol. 31 27-33.

Griffiths G A and Clausen B 1997 Streamflow recession in basins with multiple water storages; J. Hydrol. 190 60-74.

Helsel D R and Hirsch R M 2002 Statistical Methods in Water Resources; U. S. Geological Survey Open-File Rep. $1-50$.

Kiraly L 2003 Karstification and Groundwater Flow; Speleogenesis and Evolution of Karst Aquifers 1 (3) Available at: http://www.speleogenesis.net.

Mishra A, Hata T and Abdelhadi A W 2004 Models for recession flows in the upper Blue Nile River; Hydrol. Process. 18 2773-2786.

Pajic S and Clements K A 2005 Power system state estimation via globally convergent methods; IEEE Trans. on Power Syst. 4 1683-1689.

The MathWorks 2005 Curve fitting toolbox for use with MATLAB ${ }^{\circledR}$ User's Guide.

Turkish State Hydraulic Works (DSI) 1961-2001 Stream Gauging Annuals.

Werner P W and Sundquist K J 1951 On the Groundwater Recession Curve for Large Water-sheds; IAHS General Assembly (Brussels: IAHS Publ.) 33 202-212.

Wittenberg H 1999 Baseflow recession and recharge as nonlinear storage processes; Hydrol. Process. 13 715-726.

Wittenberg H 2003 Effects of season and man-made changes on baseflow and flow recession: case studies; Hydrol. Process. 17 2113-2123.

Yuan Y X 1994 Nonlinear Programming: Trust Region Algorithms; (eds) Xiao S T and Wu F, Proceedings of Chinese SIAM Annual Meeting Hsinghua University Beijing, 1-20. 